\title{
Efficacy of rhomboid intercostal block for analgesia after thoracotomy
}

\author{
Korgün Ökmen \\ Department of Anesthesiology and Reanimation, University of Health Sciences, \\ Bursa Yuksek Ihtisas Training and Research Hospital, Bursa, Turkey
}

\begin{abstract}
Regional anesthesia, including central and plane blocks (serratus anterior plane block and erector spinae block), are used for post-thoracotomy pain. The rhomboid intercostal block (RIB) is mainly performed by injection to the upper intercostal muscle plane below the rhomboid muscle. It has been reported to provide analgesia at the T3-T9 levels. The RIB was performed on 5 patients who had been scheduled for thoracotomy. The catheter was advanced in the area under the rhomboid muscle between the intercostal muscles. Postoperative visual analog scale (VAS) scores were observed and each patient's resting VAS score remained below 3 for 48 hours. The RIB has been observed to be a convenient plane block for post-thoracotomy analgesia. We believe that further information from detailed studies is required. (Korean J Pain 2019; 32: 129-32)
\end{abstract}

Key Words: Analgesia; Catheters; Fascia; Intercostal muscle; Thoracotomy; Pain management; Pain measurement; Postoperative pain; Ribs; Rhomboid major muscle; Visual analog scale.

Plane blocks have been popular among regional anaesthesiologists. They have been recently used for various surgical procedures [1]. Plane blocks, such as the serratus anterior plane (SAP) block, pectoral nerve block, and erector spinae plane block, can be used in surgical procedures involving the thoracic wall. The analgesic applications performed after thoracotomy operations (which are considered major surgical procedures) consist of multimodal regimes [2]. The medical literature includes various publications that share the successful results of the SAP block performed for post-thoracotomy analgesia. The rhomboid in- tercostal block (RIB) is applied in the area defined as the triangle of auscultation located on the medial edge of the scapula. This area is bounded by the lower border of the trapezius muscle, medial margin of the scapula, and the latissimus dorsi [3]. The RIB is mainly performed by injection to the upper intercostal muscle plane and below the rhomboid muscles. Elsharkawy et al. [3] had performed it for pain relief in a patient with multiple rib fractures.

In this report, we intended to share the results of 5 patients on whom we performed an RIB and insertion of catheter.

Received November 29, 2018. Revised January 23, 2019. Accepted January 24, 2019.

Correspondence to: Korgün Ökmen

Department of Anesthesiology and Reanimation, University of Health Sciences, Bursa Yuksek Ihtisas Training and Research Hospital, Mimar Sinan Mah. Emniyet Street Yildirim, Bursa 16130, Turkey

Tel: +90-224-295-5000, Fax: +90-224-295-54-97, E-mail: korgunokmen@gmail.com

ORCID: https://orcid.org/0000-0001-8546-4661

() This is an open-access article distributed under the terms of the Creative Commons Attribution Non-Commercial License (http:// creativecommons.org/licenses/by-nc/4.0/), which permits unrestricted non-commercial use, distribution, and reproduction in any medium, provided the original work is properly cited.

(C) The Korean Pain Society, 2019 


\section{CASE REPORT}

Four male patients and 1 female patient with average age of $57.4 \pm 4.5$ years were scheduled to have posterolateral thoracotomy for lobectomy surgery due to lung cancer (Table 1). The patients were informed about the RIB before the operation. Written consent from the patients was obtained. The visual analog scale (VAS; 0: no pain, 10: maximal pain) was explained. Non-invasive blood pressure, electrocardiography, pulse rate, and peripheric oxygen saturation monitorization were monitored. Two to 2.5 $\mathrm{mg} / \mathrm{kg}$ propofol and $0.6-0.8 \mathrm{mg} / \mathrm{kg}$ rocuronium bromide was administered intravenously for induction. The patients were intubated with a double-lumen tube of proper size (35-37 French) and mechanic ventilation was performed to the point where end-tidal $\mathrm{CO}_{2}$ was $30-35 \mathrm{mmHg}$. Sevoflurane (concentration 2\%-2.5\%) was given within an $\mathrm{O}_{2}$-air mixture at the flow velocity of $3 \mathrm{~L} / \mathrm{m}$. The need for additional analgesic medication was fulfilled with $1 \mu \mathrm{g} / \mathrm{kg}$ fentanyl. The operation was performed in the intercostal space posterolaterally. The block was performed after the operation was over and skin incision was closed. The first postoperative $24 \mathrm{~h}$ was tracked in the post-anesthesia care unit.

RIB procedure: After proper site clearance, the scapula was placed vertically on the lower medial area, defined as the auscultation triangle, in a cranio-caudal direction with the linear ultrasound probe in a sagittal position. The rhomboid major muscle was distinguished at the level of the $\mathrm{T} 6$ and $\mathrm{T} 7$ vertebrae, below the trapezius muscle. After the location was confirmed through hydrodissection of 3 $\mathrm{ml}$ on the upper intercostal muscles under the rhomboid major muscle via a 20-gauge $100 \mathrm{~mm}$ ultrasound-visible peripheral nerve block needle (Quincke Sono Plex Pajunk, Geisingen, Germany) using an in-plane technique, plane technique, $20 \mathrm{ml}$ of bupivacaine (concentration 0.25\%) was injected and a $22 \mathrm{G}$ catheter was advanced under the rhomboid major muscle [3] (Figs. 1, 2).

Postoperative pain treatment: $20 \mathrm{mg}$ of tenoxicam was scheduled to be injected intravenously before the operation was completed and $24 \mathrm{~h}$ after the operation. In addition, bupivacaine-added saline solution $(1 \mathrm{mg} / \mathrm{ml})$ was given with a patient-controlled analgesia device and the basal infusion was performed at a rate of $5 \mathrm{ml} / \mathrm{h}$ via the catheter. Tramadol and paracetamol were given as rapid analgesics to patients with VAS scores of 4 or higher. VAS scores, total amount of analgesics given, and side effects were measured at the $2^{\text {nd }}, 6^{\text {th }}, 12^{\text {th }}, 24^{\text {th }}, 30^{\text {th }}, 36^{\text {th }}$, and $48^{\text {th }} \mathrm{h}$. When the VAS scores were examined, resting VAS values higher than 3 were not found in any of the patients

Table 1. Demographic Characteristics, VAS Score and Analgesic Requirement

\begin{tabular}{|c|c|c|c|c|c|}
\hline Variable & Patient 1 & Patient 2 & Patient 3 & Patient 4 & Patient 5 \\
\hline \multicolumn{6}{|l|}{ Demographic characteristic } \\
\hline Age $(y)$ & 56 & 61 & 63 & 52 & 55 \\
\hline Body mass index $\left(\mathrm{kg} / \mathrm{m}^{2}\right)$ & 23.55 & 22.49 & 21.87 & 22.41 & 23.03 \\
\hline Sex & Male & Male & Female & Male & Male \\
\hline Amount of opioid given during operation $(\mu \mathrm{g})$ & 100 & 150 & 125 & 100 & 100 \\
\hline \multicolumn{6}{|l|}{ VAS at rest/at movement } \\
\hline $2 \mathrm{~h}$ & $2 /-$ & $2 /-$ & $2 /-$ & $2 /-$ & $2 /-$ \\
\hline $6 \mathrm{~h}$ & $2 /-$ & $2 /-$ & $2 /-$ & $2 /-$ & $1 /-$ \\
\hline $12 \mathrm{~h}$ & $3 / 5$ & $1 / 3$ & $3 / 4$ & $2 / 3$ & $1 / 4$ \\
\hline $24 \mathrm{~h}$ & $2 / 4$ & $1 / 3$ & $2 / 4$ & $1 / 2$ & $1 / 3$ \\
\hline $30 \mathrm{~h}$ & $1 / 3$ & $1 / 2$ & $1 / 3$ & $1 / 3$ & $1 / 3$ \\
\hline $36 \mathrm{~h}$ & $1 / 2$ & $1 / 3$ & $2 / 4$ & $1 / 3$ & $1 / 2$ \\
\hline $48 \mathrm{~h}$ & $1 / 2$ & $1 / 3$ & $2 / 3$ & $1 / 3$ & $1 / 2$ \\
\hline \multicolumn{6}{|l|}{ Additional analgesic requirement (48 h) } \\
\hline Paracetamol & 1 & - & 1 & - & - \\
\hline Tenoxicam (mg) & 40 & 40 & 40 & 40 & 40 \\
\hline Tramadol (mg) & 50 & - & 75 & - & 50 \\
\hline Dermatomal effect & T2-T8 & Т3-Т8 & T3-T7 & T2-T9 & T2-T8 \\
\hline
\end{tabular}

VAS: visual analogue scale (0: no pain, 10: the worst pain imaginable). 

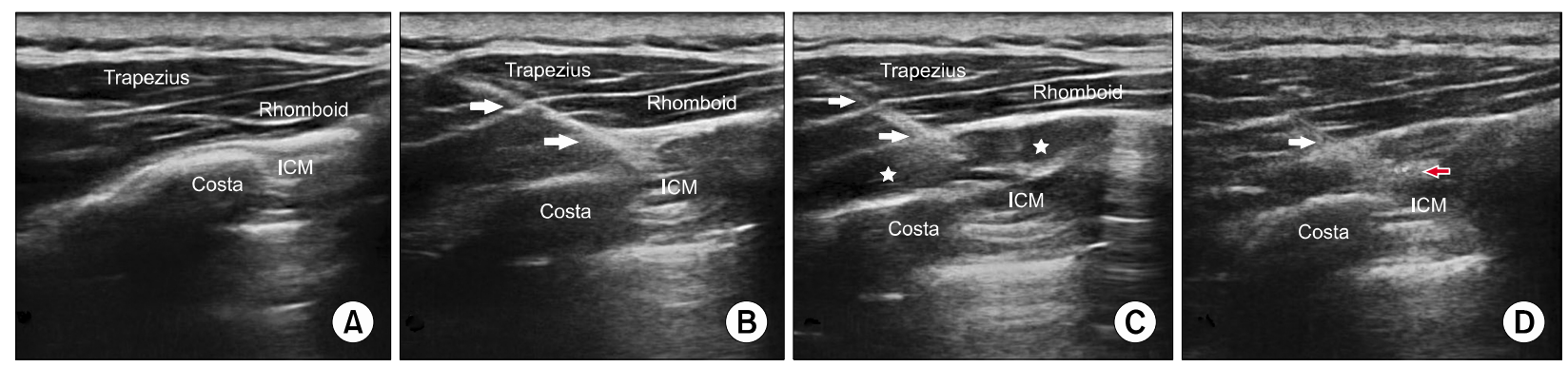

Fig. 1. Rhomboid intercostal block. (A) Ultrasound anatomy. (B) An ultrasound-visible block needle was inserted. (C) White stars indicate local anesthesic spread between the rhomboid major muscle and intercostal muscle. (D) White arrow indicates the catheter inserted. Color doppler imaging shows the local anesthesic spread. ICM: intercostals muscle.

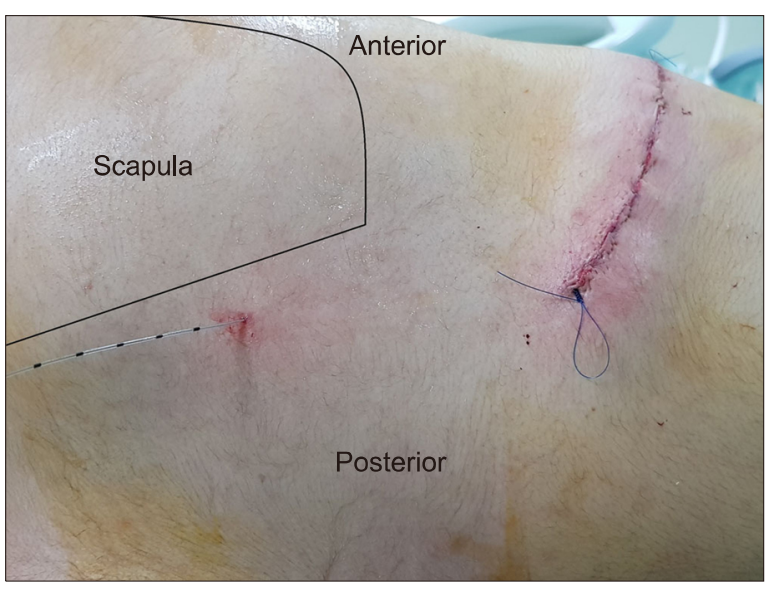

Fig. 2. The inserted catheter and surgical field.

for $48 \mathrm{~h}$. In 2 out of 5 patients, low-dose opioid (tramadol $50 \mathrm{mg}, 75 \mathrm{mg}$ ) and $1 \mathrm{~g}$ of paracetamol were required. Only tramadol was administered in one patient. In two cases, no additional analgesic was needed except the local anaesthetic (LA) which was applied during the block using infusion. At the postoperative $30 \mathrm{~min}$ after operation, the cold test was performed and the appropriate sensory block was determined between T2 and T9 levels. No complication was observed in any patient (Table 1).

\section{DISCUSSION}

Plane blocks have recently replaced the thoracic epidural block, which was previously the gold standard for post-thoracotomy pain. Despite the limited knowledge of it in the medical literature, there have been successful retrospective and randomized controlled trial studies where the serratus plane block was used in cases of thoracotomy and other operations involving the thoracic wall as a postoperative analgesia [4,5]. Results of such studies, which especially compare the efficiency of the SAP block with thoracic epidural analgesia, indicate that the SAP block provides a similar level of analgesia compared to thoracic epidural analgesia. The RIB was defined by Elsharkawy et al. [6]. They tried to determine, in patients, as well as on cadavers, the spread of dye and the effect of LA injected between the rhomboid major muscle and intercostal muscle.

They observed that $25 \mathrm{ml}$ methylene blue spread in a cranial and caudal direction, at the T2-T8 levels under the rhomboid muscle, to the posterior primary ramus located close to the intercostal nerves at the 3rd and 8th thoracic levels. The effect of LA applied between the rhomboid muscles and intercostal muscles occurs in mainly two ways.

First, the LA spread along the serratus anterior muscle blocks the lateral cutaneous branches of the intercostals nerve. Secondly, LA spreads in the medial direction, and covers the thoracic nerve and dorsal rami [1].

Case reports show that an RIB performed with $25 \mathrm{ml}$ bupivacaine at $0.25 \%$ concentration on a patient with multiple rib fractures provided sensory block and symptomatic relief at the T2-T9 levels in the lateral, posterior, and midanterior hemithorax. The RIB was performed to relieve the pain after surgery in the subscapular region in another case report shared in the medical literature. A block was performed with a $30 \mathrm{ml}$ LA mixture $(20 \mathrm{ml}$ bupivacaine + $10 \mathrm{ml}$ lidocaine) and it provided a successful postoperative analgesia (VAS 2/10) [7]. The RIB's advantages in comparison to the SAP block were stated as the distance from the injection point to the surgical incision, a low possibility 
that the catheter could advance to reach the surgical area, the blockage of the lateral cutaneous branch, and the absence of long thoracic nerve blockage, unlike the surface serratus plane block [6]. The block we performed led to a sensory block at the levels of T3-T7 in all 5 patients; nevertheless, block spread levels varied. The fact only 2 cases in the literature performed the block at a volume of 20 $\mathrm{ml}$ might explain why the block spread levels differed. We believe that the infusion given via a catheter prolonged the block duration.

We believe that the RIB may have a similar level of effectiveness to other plane blocks performed on the thoracic region. Data from on-going studies are still required.

\section{CONFLICT OF INTEREST}

No potential conflict of interest relevant to this article was reported.

\section{REFERENCES}

1. Chin KJ, McDonnell JG, Carvalho B, Sharkey A, Pawa A,
Gadsden J. Essentials of our current understanding: abdominal wall blocks. Reg Anesth Pain Med 2017; 42: 133-83.

2. Kavanagh BP, Katz J, Sandler AN. Pain control after thoracic surgery. A review of current techniques. Anesthesiology 1994; 81: 737-59.

3. Elsharkawy H, Saifullah T, Kolli S, Drake R. Rhomboid intercostal block. Anaesthesia 2016; 71: 856-7.

4. Khalil AE, Abdallah NM, Bashandy GM, Kaddah TA. Ultrasound-guided serratus anterior plane block versus thoracic epidural analgesia for thoracotomy pain. $J$ Cardiothorac Vasc Anesth 2017; 31: 152-8.

5. Ökmen K, Ökmen BM. The efficacy of serratus anterior plane block in analgesia for thoracotomy: a retrospective study. J Anesth 2017; 31: 579-85.

6. Elsharkawy H, Maniker R, Bolash R, Kalasbail P, Drake RL, Elkassabany N. Rhomboid intercostal and subserratus plane block: a cadaveric and clinical evaluation. Reg Anesth Pain Med 2018; 43: 745-51.

7. Tulgar S, Thomas DT, Deveci U, Özer Z. Ultrasound guided rhomboid intercostal block provides effective analgesia for excision of elastofibroma extending to the subscapular space: the first report of use in anesthesia practice. J Clin Anesth 2019; 52: 34-5. 